\title{
Communications to the Editors
}

\section{STEREOGHEMIGAL CHARAGTERISTICS OF VARIOTIN AS DEDUGED FROM THE NUGLEAR OVERHAUSER EFFECT IN THE NMR SPECTRA}

\section{Sir :}

Variotin, an antifungal antibiotic produced by Paecilomyces varioti BAINIER var. antibioticus, has the molecular formula $\mathrm{C}_{17} \mathrm{H}_{25} \mathrm{O}_{3} \mathrm{~N}^{1,2)}$. From chemical and nmr spectroscopic properties the structure of $\mathrm{N}-\left(8^{\prime}-\mathrm{R}-\right.$ hydroxy$6^{\prime}$-methyl-trans-trans-cis-dodeca- $2^{\prime}, 4^{\prime}, 6^{\prime}$ trienoyl)-2-pyrrolidone was proposed for $\operatorname{variotin}^{3,4,5)}$.

Variotin has a conjugated triene system in its molecule. Coupling constants in the nmr spectrum indicated a trans-trans configuration in the $2^{\prime}$ and $4^{\prime}$ double bonds. The configuration of the $6^{\prime}$ double bond could not be assigned from the nmr, because there is no proton at the $6^{\prime}$ position.

Reaction of variotin with maleic anhydride by refluxing in toluene resulted in a DielsAlder type adduct, consuming one mole of the maleic anhydride. The product obtained as white needles $\left(\mathrm{C}_{21} \mathrm{H}_{27} \mathrm{O}_{6} \mathrm{~N}\right)$, is a monocarboxylic acid (pKmcs 9.75) with no free hydroxyl in the $8^{\prime}$ position. From chemical and spectroscopic studies, lactone formation between the $8^{\prime}$ hydroxy and a carboxyl group of one of two carboxyls in the adduct was confirmed. Ozonolysis of the adduct yielded $\mathrm{D}-\alpha$-hydroxy caproic acid as was obtained from variotin. Thus the $6^{\prime}$ double bond must not have been affected. Accordingly, the authors concluded that the $6^{\prime}$ double bond must have a cis configuration $^{5)}$.

The intramolecular nuclear Overhauser effect (NOE) in the nmr spectrum has now been utilized to determine the configuration of the $6^{\prime}$ double bond in variotin. The application of the NOE technique to natural products was evaluated by Woops and others ${ }^{6)}$. Calculating from a Dreiding model with the cis configuration at $6^{\prime}$, the distance between the $13^{\prime}$ methyl and the $7^{\prime}$ olefinic proton is approximately $2.3 \AA$. Irradiation of one of these protons should increase the intensity or area of the signal of the proximal protons. On the other hand, because of the distance from the $13^{\prime}$ methyl to the $8^{\prime}$ proton in the cis structure, a significant NOE would not be expected with these protons. With a trans configuration at $6^{\prime}$, the distance between the $13^{\prime}$ methyl and the $7^{\prime}$ proton is approximately $3.4 \AA$, and the distance from the $13^{\prime}$ methyl to the $8^{\prime}$ proton is about 1.6 $\AA$, thus the NOE would be expected with the protons in the $13^{\prime}$ methyl and the $8^{\prime}$ proton.

To determine the NOE of variotin, the $\mathrm{nmr}$ spectra were taken at $100 \mathrm{MC}$ and a concentration of $100 \mathrm{mcg} / \mathrm{ml}$ in deuterated benzene using tetramethylsilane (TMS) for frequency lock. By the irradiation of the $13^{\prime}$ allylic methyl signal at $1.65 \mathrm{ppm}$ from TMS, the increase in the integrated area due to the $7^{\prime}$ doublet at $3.1 \mathrm{ppm}$ was insignificant. On the contrary, the integrated intensity of the quartet signal due to the $8^{r}$ was increased about $12 \%$ and the total area of signals due to the $4^{\prime}$ which overlaped with $5^{\prime}$ the olefinic proton at $6.4 \mathrm{ppm}$ was increased about $9 \%$ by the same irradiation.

From the results of NOE values it is concluded that the $8^{\prime}$ proton is closer than the $7^{\prime}$ proton to the $13^{\prime}$ methyl group. Accordingly, the configuration of the $6^{\prime}$ double bond of variotin should be assigned as the trans form.

The results obtained from the intramolecular NOE in variotin is contrary to the previous chemical result. The authors consider that such a discrepancy may arise by stereochemical change at the $6^{\prime}$ double bond during the Diels-Alder reaction. The structure of variotin is thus revised to $\mathrm{N}-\left(8^{\prime}-\mathrm{R}-\right.$ hydroxy- $6^{\prime}$-methyl-trans-trans-trans-dodeca$2^{\prime}, 4^{\prime}, 6^{\prime}$-trienoyl)-2-pyrrolidone.

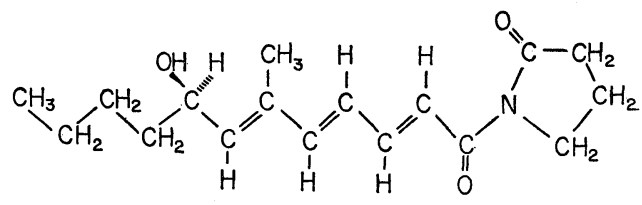


The authors wish to express their hearty sincere appreciation to Dr. Y. Kishida and Mr. H. Kuwano, Central Institute of Sankyo Co., Ltd. for their NOE measurement.

\author{
Setsuo Takeuchi \\ Hiroshi Yonehara \\ Institute of Applied Microbiology, \\ The University of Tokyo, \\ Bunkyo-ku, Tokyo, Japan \\ (Received February 18, 1969)
}

\section{References}

1) Yonehara, H.; S. Takeuchi, H. Umezawa \& Y. Sumiki : Variotin, a new antifungal antibiotic, produced by Paecilomyces varioti BAINIER var. antibioticus. J. Antibiotics, Ser. A $12: 109 \sim 110,1959$
2) Takeuchi, S.; H. Yonehara \& H. Umezawa : Studies on variotin, a new antifungal antibiotic. I. Preparations and properties of variotin. J. Antibiotics, Ser. A $12: 195 \sim$ 200, 1959

3) Takeuchi, S. \& H. Yonehara: Studies on variotin, a new antifungal antibiotic. III. Chemical structure of variotin. J. Antibiotics, Ser. A $14: 44 \sim 53,1961$

4) Takeuchi, S.; H. Yonehara \& H. Shoji : Crystallized variotin and its revised chemical structure. J. Antibiotics, Ser. A 17 : $267 \sim 268,1964$

5) Takeuchi, S. \& H. Yonehara : Stereochemistry of variotin. Tetrahedron Letters 1966$42: 5197 \sim 5200,1966$

6) Woods, M. C.; I. MiUra, Y. Nakadaira, A. Terahara, M. Maruyama \& K. Nakanishi : The ginkgolides. V. Some aspects of their NMR spectra. Tetrahedron Letters 1967-4 : 321 326, 1967 